\title{
Improving Wet-Weather Runway Performance Using Trapezoidal Grooving Design
}

\author{
H. R. Pasindu ${ }^{1}$ T. F. Fwa ${ }^{2,3}$
}

Received: 1 April 2015/Accepted: 26 May 2015/Published online: 4 June 2015

(C) Springer International Publishing AG 2015

\begin{abstract}
Runway operational safety is a key concern of all airport authorities. As more and more new airports are developed and existing airports expanded in developing countries to cope with the rapidly increased air traffic driven by economic growth and declining air travel costs, the responsibility of the airport operators and aviation authorities to ensure safety in aircraft operations has become increasingly challenging. One important means of enhancing runway operational safety is pavement grooving which has been widely accepted as an effective measure that reduces aircraft hydroplaning risk and the loss of pavement skid resistance during wet weather. In 2012, a new trapezoidal grooving design was tested by Federal Aviation Administration (FAA) and was found to offer several benefits over the conventional square grooving design, including greater resistance to rubber contamination, better integrity, and improved longevity. This paper evaluates the findings of a recent analytical study and a field trial conducted in Singapore to provide further insights into the possible operational safety and maintenance benefits of using trapezoidal-shaped grooves in runway pavements. The results of the evaluation suggest that trapezoidal grooving would be beneficial to airports of
\end{abstract}

T. F. Fwa

ceefwatf@nus.edu.sg

1 Department of Civil Engineering, University of Moratuwa, Katubedda, Moratuwa, Sri Lanka

2 Department of Civil \& Environmental Engineering, Centre for Transportation Research, National University of Singapore, Singapore, Singapore

3 Department of Civil Engineering, National University of Singapore, 1 Engineering Drive, Singapore 117576, Singapore developing countries to achieve good operational safety with reasonable runway pavement maintenance efforts.

Keywords Runway safety - Runway grooving · Trapezoidal groove $\cdot$ Square groove Skid resistance . Hydroplaning

\section{Introduction}

Runway excursions, including skidding and overruns of aircraft, constitute a significant part of aircraft related accidents in airports worldwide. Because such accidents often involve a relatively large number of passengers, aircraft landing and take-off safety on runways has been a key area of focus of the airport operators and aviation authorities of all major airports in the world. In the developing world, this issue is also attracting increasing attention as more and more new airports are developed and existing airports expanded to cope with the rapidly increased air traffic driven by economic growth and declining air travel costs.

Central to the effort of providing a safe runway for aircraft operations is to ensure that the skid resistance of the runway pavement is maintained at a sufficiently high level for all weather conditions. Researchers have identified runway skid resistance performance as a main causal factor of runway excursions [1-3]. As a result, there have been strict requirements from major organizations such as International Civil Aviation Organization (ICAO) and Federal Aviation Administration (FAA) concerning runway pavement surface texture and friction characteristics to ensure safe aircraft operations $[4,5]$. One of the methods widely applied in the major airports in the United States and in many parts of the world is to cut transverse grooves on the surface of runway pavements to improve its 
frictional properties and reduce hydroplaning risk under wet pavement conditions [6-8]. A design of square grooves specified by FAA has been the de-facto standard adopted worldwide for many years since it was published in the 1980s [5].

Experiences with the use of grooved asphalt pavements have shown that despite the definite benefits in achieving improved aircraft operational safety on runways, there were maintenance and durability issues associated with groove related distresses. The most common forms of groove related distresses are groove wear, groove closure, groove migration, groove collapse, and rubber deposits [912]. As an attempt to mitigate the problems caused by these groove related distresses, FAA experimented with a new trapezoidal grooving design in 2012 and concluded that the new grooving design offered better performance in terms of groove stability and longevity [13]. This paper reports the findings of two recent studies conducted in Singapore to provide further insights into the possible operational safety and maintenance benefits of using trapezoidalshaped grooves in runway pavements.

\section{Benefits of Grooving Runway Pavements}

In an effort to reduce aircraft risks of skidding, overrun or hydroplaning during landing or take-off to a sufficiently low level, ICAO imposes several requirements on the surface characteristics of runway pavements [4]. The following are three recommendations most directly related to these requirements:

(a) Minimum pavement friction-ICAO requires that friction tests of existing runway pavement surface conditions be taken periodically to avoid having pavement friction falling below the minimum friction level specified by the airport in accordance with ICAO recommendations. The friction is measured with a device having self-wetting features to allow measurements of the surface friction characteristics to be made at a water depth of $1 \mathrm{~mm}$.

(b) Minimum surface texture depth-ICAO recommends that airports seek to achieve an average surface texture depth of E classification, i.e. having a mean texture depth of not less than $1.0 \mathrm{~mm}$.

(c) Maximum surface water depth-ICAO indicates that pools of water as shallow as $3 \mathrm{~mm}$ in depth can induce aquaplaning for airplanes landing at high speeds. An airport must report this situation of standing water in the description of the runway surface condition.

An airport can improve its runway operational safety with respect to the three above-mentioned requirements by grooving the runway pavement. Grooving can reduce the loss of tyre-pavement friction in wet-weather in two ways: by reducing the water-film thickness on the pavement surface because of the higher drainage discharging capacity of a grooved surface; and by the better ability of a grooved surface to reduce the build-up of hydrodynamic pressure at the tyre-pavement interface.

The advantage of higher drainage capacity of a grooved surface also means that during a given rainfall, the maximum surface water depth on a grooved pavement surface will be less than that on an ungrooved pavement surface. In other words, grooving a runway surface helps to reduce the length of time that a runway pavement will have surface water thicker than $3 \mathrm{~mm}$. This translates to longer operating hours of a runway, particularly for airports in regions exposed to heavy or torrential rainfalls.

As for surface texture depth, grooving is one of the most effective ways of overcoming the problem of insufficient texture depth of a typical dense-graded asphalt wearing course. The presence of grooves in a pavement surface, with regular maintenance to ensure its high drainage capacity, practically eliminates the occurrence of hydroplaning for the normal range of landing and take-off speeds of most commercial aircraft [14].

\section{Maintenance Issue of Grooved Pavements}

The effectiveness of a grooved runway pavement may deteriorate with time under the effect of aircraft traffic loading. The benefits of grooving, namely the high drainage capacity and deep overall effective texture depth, can be significantly reduced by groove related distresses such as wear and tear of groove walls, groove closure, groove migration, groove collapse, and rubber deposits [9-12]. These are the common distresses that are known to have affected the performance of grooved runway pavements.

Wear and tear of grooves occurs in the form of chipping and spalling of edges of grooves, loss of coarse aggregates along groove walls, rounding off of the edges of grooves, and erosion that washes out the fines or the asphalt binder leaving only exposed aggregates in the grooves. These distresses lead to disfiguring of the grooves. Besides reducing the drainage effectiveness of the grooves, they affect the riding quality of the pavement, and may pose foreign object damage (FOD) danger. These problems can be mitigated by improving either the asphalt mix design or the geometric configuration of the grooves.

Groove closure refers to the closing up of grooves caused by deformation of the asphalt mixture of individual grooves leading to reductions of groove widths. Groove collapse happens when there is a general breaking up or disintegration of the surface asphalt mixture of the grooved 
pavements. Groove migration is caused by traffic induced horizontal movements of pavement surface mixtures resulting in a wavy groove pattern. All three forms of distress have direct negative impacts on the drainage capacity of the grooved pavement affected. They can be controlled by improving the design of the asphalt mixture. It is possible that a change of groove configuration might help in reducing the occurrence and extent of groove closure and groove collapse.

Rubber contamination of runway landing zone occurs due to rubber deposit accumulation from wear and tear of rubber tyres during aircraft landing. On an ungrooved pavement, rubber deposit causes a loss of tyre-pavement friction and may even lead to reverted rubber hydroplaning [15]. Grooving a runway pavement surface helps to lessen the negative impact of rubber deposits on tyre-pavement friction, and reduce the risk of reverted rubber hydroplaning. Rubber deposits on runway pavement surface have to be removed periodically before the friction value falls below a pre-specified level. Rubber deposits can be removed by applying high pressure water jet, chemical solvent, abrasive blasting, or mechanical means such as milling or grinding. Any of these methods if applied inappropriately may cause some damages to the grooves.

\section{Studies on Performance of Square- and Trapezoidal-Grooved Pavements}

After an extensive series of experimental studies on the significant improvements in hydroplaning and skid resistance of grooved runways over ungrooved ones, FAA recommended in the 1997 edition of its Advisory Circular AC 150/5320-12C [5] a standard saw-cut square groove to be installed in all runways serving turbojet aircraft. However, experience with its use reveals some maintenance problems related to deterioration of grooves over time caused by aircraft loading and repeated rubber deposit removal operations.

The recently completed FAA study on trapezoidal grooves showed that the trapezoidal-shaped pavement groove design offered several benefits over the current FAA standard square grooves, including improved water evacuation capability, greater resistance to rubber contamination, better integrity, and improved longevity [12]. Figure 1 shows the cross-sectional dimensions of the square and trapezoidal grooving designs. However, due to experimental constraints of field tests and the range of inherent measurement errors of measuring devices, the study could not reach any definite conclusion on the relative skid resistance and hydroplaning performance of the trapezoidal and square grooves. (a)

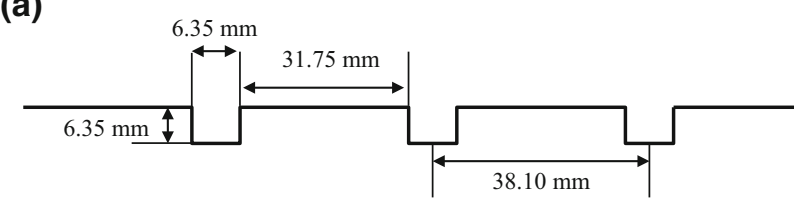

(b)

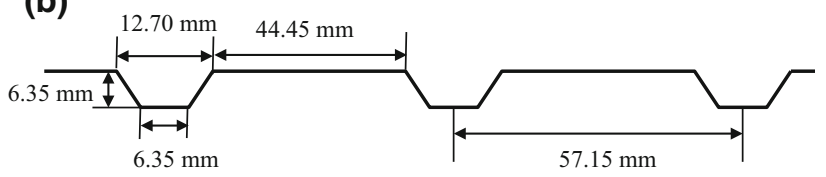

Fig. 1 Square and trapezoidal groove designs. a Dimensions of FAA square groove design. b Dimensions of alternative trapezoidal groove design

As it is important to ensure that in the process of improving the durability, integrity and longevity of the grooves, the safety performance (skid resistance and hydroplaning risk in particular) of the grooved pavement is not compromised, it is critical to determine if the trapezoidal groove design would provide satisfactory skid resistance and hydroplaning performance compared to the standard square groove design. The following sections presents the findings of two studies conducted in Singapore with the aim to predict the performance of trapezoidal grooves with respect to that of the standard square grooves.

The first study is an analytical study that predicts the drainage capacities, as well as the relative skid resistance and hydroplaning performances of the two groove designs by means of 3-dimensional finite element simulation models. The second study is a field trial constructed on a runway of the Singapore Changi Airport to evaluate the relative performance of square and trapezoidal grooved pavement sections under actual aircraft traffic.

\section{Analytical Study of Wet-Weather Performance of Square- and Trapezoidal-Grooved Pavements}

There are two main aspects that affect the wet-weather performance of a grooved pavement:

(i) The hydraulic properties of the grooves as drainage channels to discharge runoff during a rainfall. These properties will determine the thickness of flowing water on the pavement surface, as well as the ease in discharging (i.e. the rate of discharge) surface water underneath a moving tyre. Both have direct impacts on the skid resistance available to and the hydroplaning speed of a vehicle moving on the grooved pavement.

(ii) The skid resistance and hydroplaning characteristics of the grooved pavement, which are affected by 
the hydraulic properties of the grooves, and the magnitude of contact area between the vehicle tyre concerned and the pavement surface. The latter factor is a function of the spacing and width of opening of the grooves.

The following sub-sections present the findings of the analytical study.

\section{Hydraulic Properties of Square- and Trapezoidal Grooves}

The hydraulic properties of pavement grooves are analyzed by means of a finite element simulation model that evaluates the water flow rates of the two groove designs under the action of an aircraft tyre load. The computer software adopted for this analysis is ANSYS CFX [19]. Figure 2 shows a schematic diagram of the model for determining the flow capacity of a flooded pavement surface with a pressure inlet of water from a rectangular area representing the contact patch between an aircraft tyre and the impervious pavement surface. To cover the range of likely aircraft tyre pressures, three inlet pressures of 800,1200 and $1600 \mathrm{kPA}$ are considered. The top surface and both ends of each channel are outlet boundaries of atmospheric pressure. The bottom and side walls of each grooves are modeled as solid impervious walls. A convergence analysis of the finite element model indicated that a length of grooves equal to $0.8 \mathrm{~m}$ on both sides beyond the edge of the tyre-pavement contact patch is sufficient. Water flow is modeled by the Navier-Stokes equations [20], and $k-\varepsilon$ model [21] is adopted to capture the turbulent features of water flow beneath the tyre and within the grooves.
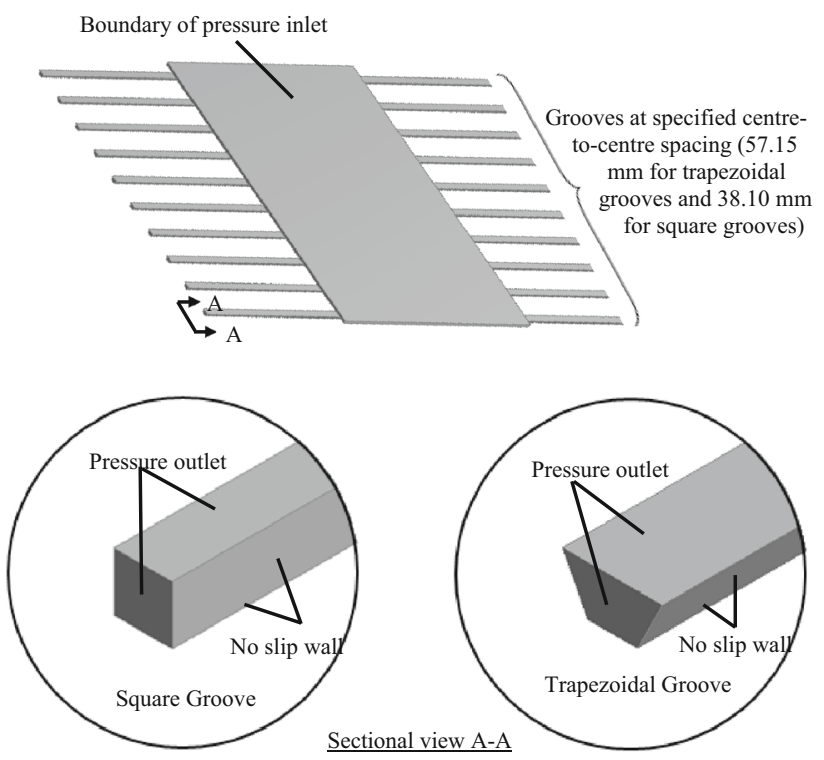

Fig. 2 Modeling of flow capacity of pavement grooves
The results of the analysis are presented in Table 1. It is seen from the results that the trapezoidal groove design has a slightly higher flow capacity which is about $4.5 \%$ more than the flow capacity of the square groove design. The difference in flow capacity of the two groove designs could be explained by comparing their hydraulic geometric properties as shown in Table 2. Although the flow channels of the two designs have identical cross-sectional areas per unit length of pavement, the trapezoidal grooves have a much wider inlet opening (32.9\% wider per unit length of pavement) which allows surface water to flow into the grooves more easily. The trapezoidal design also has a smaller wetted perimeter per unit length of pavement (28.0\% less per unit length of pavement) which offers less resistance to flow. The combined effect of wider inlet opening and smaller wetted perimeter translates to a higher drainage capacity as revealed by the finite element outflow analysis presented in Table 1.

\section{Simulation Analysis of Skid Resistance and Hydroplaning Performance}

Due to constraints of measurement accuracy and limited range of thickness of water depths possible in field measurements, the FAA field study conducted in 2012 was unable to make a comprehensive comparison of the relative skid resistance and hydroplaning performance of the square- and trapezoidal-grooved pavement surfaces. This problem could be overcome by performing an analytical evaluation of the skid resistance and hydroplaning speeds of the two types of grooved surfaces using a finite element simulation model for tyre-pavement skid resistance developed earlier by the authors [14, 16-18]. The finite element analysis computer software, ADINA [22] is used to solve the coupled tyre-fluid-pavement interaction problem. The formulation and solution of the simulation model is based on the theory of computational fluid dynamics. It simulates the tyre-fluid-pavement interaction and takes into consideration the effects of turbulence and free surface flow.

The same simulation model is used for both skid resistance and hydroplaning analysis. Figure 3 shows the main components of the finite element mesh used for the analysis. The key element in the computation of skid resistance and hydroplaning speed on a runway pavement is the determination of the hydrodynamic uplift acting on the aircraft tyres by the water wedged between the aircraft tyre and the pavement. The aircraft speed is gradually increased and the corresponding hydrodynamic uplift at each speed is calculated. Knowing the wheel load and the hydrodynamic uplift, the frictional resistance acting at the tyre-pavement contact area can be determined. The available skid resistance at the given aircraft speed may then be computed by means of the following equation: 
Table 1 Flow capacity of square and trapezoidal grooves

\begin{tabular}{llll}
\hline Inlet pressure $(\mathrm{kPa})$ & \multicolumn{2}{l}{ Flow rate $\left(\times 10^{-3} \mathrm{~m}^{3} / \mathrm{s}\right)$} & Ratio of flow rates (trapezoidal/square) \\
\cline { 2 - 3 } & Square groove & Trapezoidal groove & \\
\hline 800 & 37.6 & 39.2 & 1.042 \\
1200 & 46.6 & 48.8 & 1.047 \\
1600 & 53.1 & 55.7 & 1.049 \\
\hline
\end{tabular}

Table 2 Comparison of hydraulic geometric properties of square and trapezoidal grooves

\begin{tabular}{lllc}
\hline Hydraulic property & Trapezoidal grooves & Square grooves & $\begin{array}{c}\text { \% Difference with } \\
\text { respect to square grooves }\end{array}$ \\
\hline Channel cross-sectional area per unit length of pavement $\left(\mathrm{mm}^{2} / \mathrm{mm}\right)$ & 0.0417 & 0.0417 & 0 \\
Channel inlet width per unit length of pavement $(\mathrm{mm} / \mathrm{mm})$ & 0.222 & 0.167 & +32.9 \\
Wetted perimeter per unit length of pavement $(\mathrm{mm} / \mathrm{mm})$ & 0.360 & 0.500 & -28.0 \\
\hline
\end{tabular}

Fig. 3 Finite-element mesh of simulation model for aircraft tire-grooved pavement skid resistance

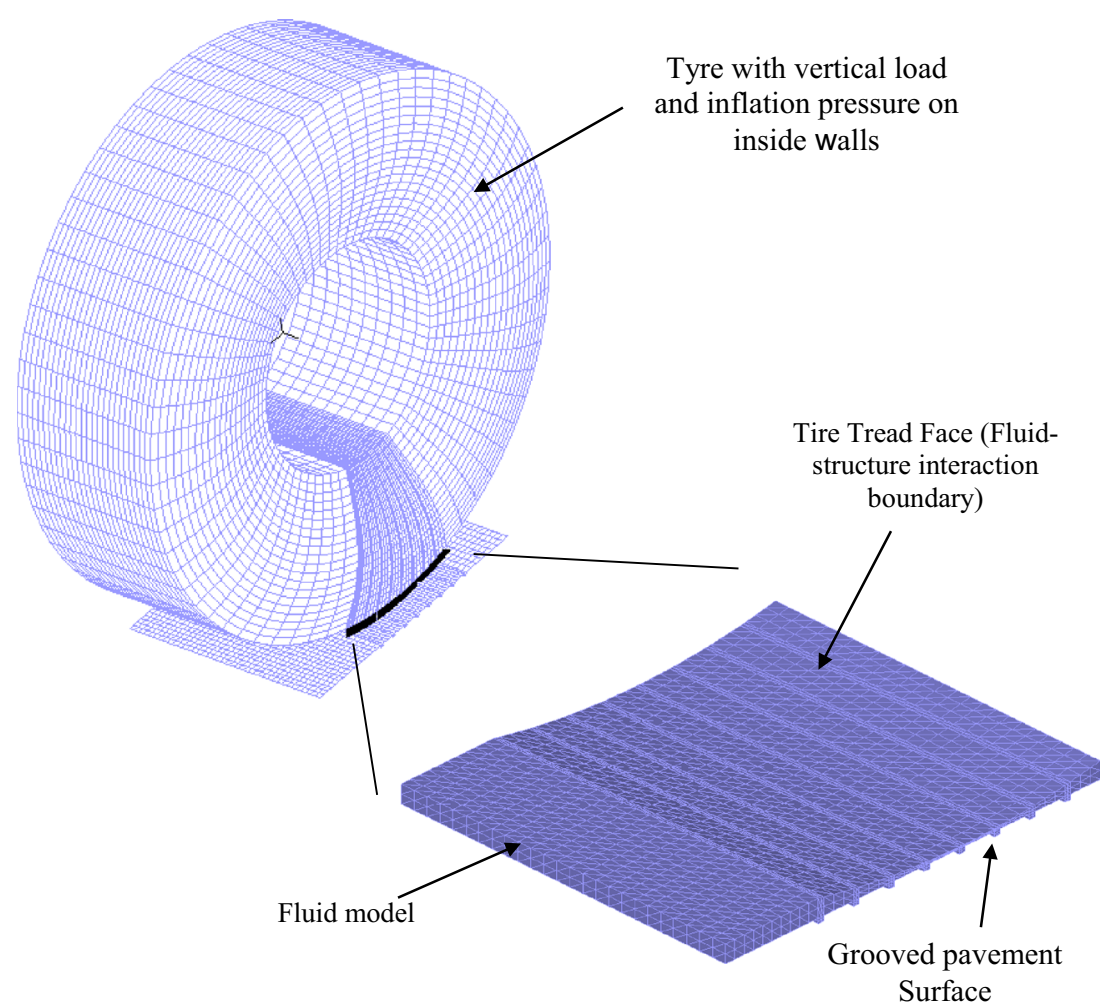

increased to a sufficiently high level that the total fluid uplift force is equal to the tyre load and there is no contact between the tyre and the pavement surface, hydroplaning is said to occur. The aircraft speed at which hydroplaning occurs is defined as the hydroplaning speed. At this speed, the aircraft will lose both braking capability and steering control. In the simulation analysis, the hydroplaning speed is determined as the speed at which the total fluid uplift force is equal to the tyre load. 
The analysis of skid resistance and hydroplaning speed considers the $49 \times 17$ Type VII smooth aircraft tyre. This tyre is used by modern jet aircrafts such as Boeing 727 . The tyre inflation pressure is $1200 \mathrm{kPa}$, and the wheel load is $125 \mathrm{kN}$. The detailed characteristics of the tyre model used in the simulation analysis are found in the authors' earlier work on runway pavement skid resistance studies [14].

\section{Results of Skid Resistance and Hydroplaning Speed Analysis}

The simulation analysis is performed for two pavement types with different initial static skid resistance values, one with initial skid number of $\mathrm{SN}_{0}=70$, and another with $\mathrm{SN}_{0}=55$. They represent two scenarios of pavement condition: a high-friction surface and a moderate-friction surface. The results of skid resistance simulation are plotted in Fig. 4.

As can be seen from Fig. 4, at aircraft speeds lower than about $100 \mathrm{~km} / \mathrm{h}$, the square-grooved pavement surface is found to produce slightly higher skid resistance than the trapezoidal-grooved surface. This probably can be explained by their difference in tyre-pavement contact area and the minor effect that surface water drainage has in the low-speed range. The square-grooved has a solid surface area of $0.83 \mathrm{~m}^{2}$ per square $\mathrm{m}$ area of the pavement surface,
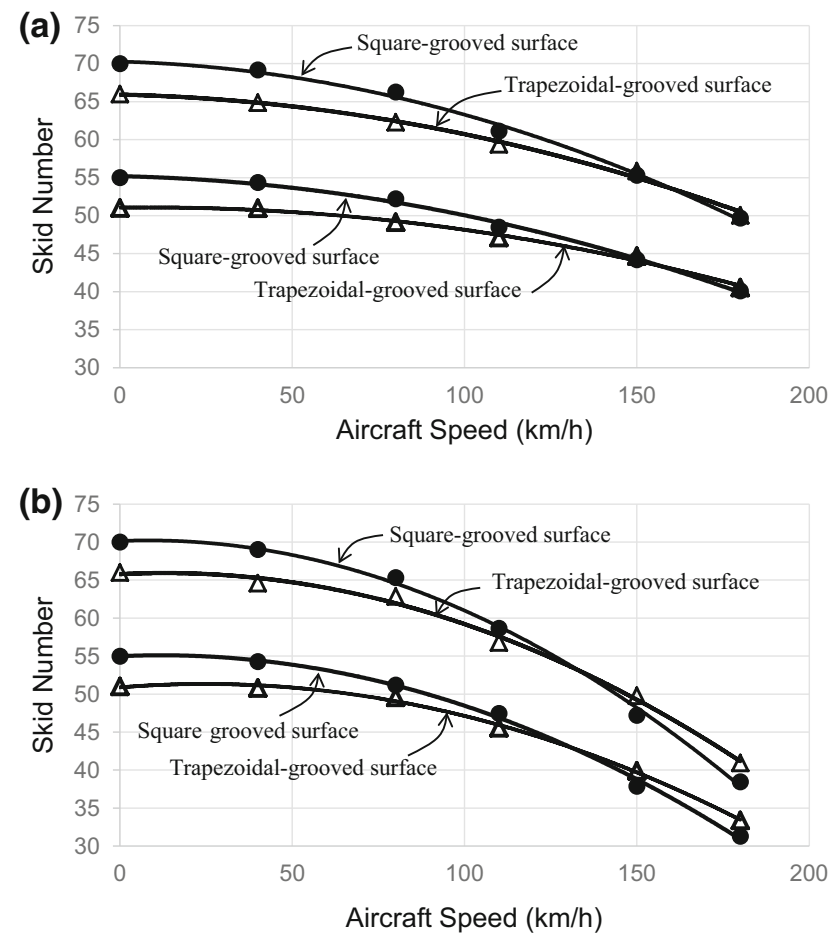

Fig. 4 Comparison of skid resistance of square- and trapezoidal-grooved surfaces. a Water depth $=5.0 \mathrm{~mm}$. b Water depth $=$ $10.0 \mathrm{~mm}$ while the corresponding solid surface area of the trapezoidal-grooved pavement is $0.78 \mathrm{~m}^{2}$. There is a difference of $6.4 \%$.

The marginally lower skid resistance of the trapezoidalgrooved surface at the speed range below $100 \mathrm{~km} / \mathrm{h}$ is not likely to present any operational issue. This is because the initial landing speeds of most aircraft are much higher than $100 \mathrm{~km} / \mathrm{h}$ although the speeds will decelerate rapidly after touching down. The results in Fig. 4 clearly indicate the slight advantage of having trapezoidal grooves during heavy rainfall. The higher drainage capacity of the trapezoidal-grooved surface helps to reduce the deterioration rate of skid resistance with aircraft speed when there is a layer of flowing water on the runway pavement surface.

Another important aspect of the requirements of a runway pavement is to provide a sufficiently high hydroplaning speed for safe landing and take-off operations of aircraft. The hydroplaning speeds predicted by the simulation model are tabulated in Table 3. Significant increases in the hydroplaning speed are achieved when grooves, either square or trapezoidal, are introduced in a runway pavement. Although the trapezoidal-grooved pavement achieves a higher hydroplaning speed than the square-grooved pavement, the difference is only about $3 \%$ which is not a magnitude of major practical significance.

Overall, the findings of the analytical study of the skid resistance and hydroplaning characteristics of the two patterns of grooved pavement suggest that there are not major differences of practical significance between them. When flooded, the square-grooved pavement has slightly higher skid resistance than the trapezoidal-grooved pavement at aircraft speeds lower than $100 \mathrm{~km} / \mathrm{h}$. Beyond $100 \mathrm{~km} / \mathrm{h}$, the trapezoidal-grooved pavement performs slightly better due to its better drainage capacity. Since the skid resistance differences of the two patterns of grooved pavements are small and of the same order of magnitude as the measurement errors of skid resistance devices, it is not surprising that the 2012 FAA field experimental study [13] could only conclude that their skid resistance performances were comparable.

\section{Field Trial Evaluation of Performance of Square- and Trapezoidal-Grooved Pavements}

In October 2014, two trial test sections of grooved pavement were installed at the Singapore Changi Airport, one was installed with FAA standard square grooves, and the other with trapezoidal grooves. The dimensions of the square and trapezoidal grooves are as given in Fig. 1. The immediate aim of the field trial were to determine if the grooved sections were able to achieve improved skid resistance and dimensional stability with the asphalt mixture 
Table 3 Comparison of hydroplaning speeds

\begin{tabular}{|c|c|c|c|}
\hline \multirow{2}{*}{$\begin{array}{l}\text { Depth of surface } \\
\text { water }(\mathrm{mm})\end{array}$} & \multicolumn{3}{|c|}{ Hydroplaning speed $(\mathrm{km} / \mathrm{h})$} \\
\hline & $\begin{array}{l}\text { Square- } \\
\text { grooved } \\
\text { surface }\end{array}$ & $\begin{array}{l}\text { Trapezoidal- } \\
\text { grooved surface }\end{array}$ & $\begin{array}{l}\text { Ungrooved } \\
\text { surface }\end{array}$ \\
\hline 5.0 & 315 & 323 & 252 \\
\hline 10.0 & 280 & 291 & 242 \\
\hline
\end{tabular}

used in the runway pavements of Singapore Changi Airport. The longer term aim was to establish the relative integrity and longevity performance of the two groove designs, as well as their respective performance with respect to maintenance requirements and ease in rubber removal. This section reports the initial conclusions related to the immediate aim of the field trial.

The field trial was carried out on an existing runway pavement of the Singapore Changi Airport. The pavement wearing surface was a dense-graded mixture produced with a polymer modified asphalt binder of Superpave performance grade PG 82-22. The field trial section was located near at one end of the runway, $400 \mathrm{~m}$ from the runway threshold. It measured $40 \mathrm{~m}$ long (along the length of the runway) and $60 \mathrm{~m}$ wide. Each of the two grooving designs covered $20 \mathrm{~m}$ by $60 \mathrm{~m}$ in plan dimensions. Both the square and trapezoidal grooves can be cut using the same set of machine by simply changing the cutting blades. There was no change in the speed and procedure of cutting. The construction and installation details of the two grooved pavement sections can be found in the report by Fwa et al. [23].

During the monitoring phase of the field trial, the following aspects of grooved pavement performance were examined: skid resistance, drainage capacity, dimensional variations of grooves, and rubber deposit build-up. The measurements and observations made in these aspects are summarized in the following paragraphs.

1. Skid resistance performance of grooved pavementsDue to the short lengths of the two grooved pavement sections, it was not possible to single out the skid resistance values of the two sections from the readings of the Saab Friction Tester (SFT) which was used for skid resistance measurements at the airport. Hence, only the average measured values for the combined grooved pavement could be reported. The measured values can be compared with the original pre-grooved skid resistance value of the pavement surface. Figure 5 compares the measured skid resistance of the grooved surface with the original value of the surface before grooving. The benefit of grooving is apparent. The skid resistance improved the skid resistance from $\mathrm{SN}$ value of 62 to as much as 70 after rubber removal. The

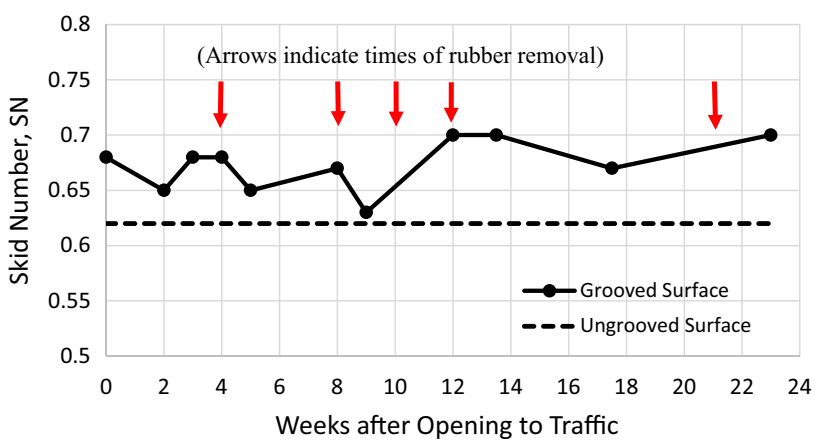

Fig. 5 Skid resistance of grooved pavement sections

improvement in skid resistance of the grooved pavement from an initial value of about 65 to 70 is believed to be due to the removal of top asphalt binder coating on the pavement surface by the combined actions of aircraft traffic and rubber removal operations.

2. Drainage capacity of grooved pavements-The drainage capacity of the grooved pavements was assessed by means of an outflow meter which consists of an $800-\mathrm{mm}$ high acrylic glass cylinder of $150 \mathrm{~mm}$ diameter with a circular metal flange at the base. The metal flange is fitted with a rubber pad to seat the cylinder tightly on a flat surface. Since the surface water flow rate on a grooved pavement is relatively high, the initial water height in the cylinder was maintained at $550 \mathrm{~mm}$ above the test surface, and the time taken for the water level to reach the mark of $250 \mathrm{~mm}$ was recorded. The total time duration per test on a grooved surface typically falls between 10 and 30 s. Figure 6 plots the flow tests taken at 4 locations each on the square- and trapezoidal-grooved pavements respectively. A total of five test measurements were made at the following times after the grooved pavements were open to traffic: $4,8,12,17$ and 18.5 weeks. The first three tests were made shortly after rubber removal operations, and the test results did not show any noticeable difference between the flow rates of the two grooved pavement surfaces. The last two sets of test results, however, suggest that rubber deposit accumulation had affected the square grooves more than the trapezoidal grooves. The trapezoidal grooves with flow durations in the range of $15-20 \mathrm{~s}$ as compared with the range of 22-30 s for the square grooves, clearly had a higher flow capacity than the square grooves when both were affected by the accumulation of rubber deposit.

3. Dimensional variations of grooves-Some slight isolated chippings and spallings of the edges of both the square and trapezoidal grooves were observed during the cutting of the grooves. These were not serious in nature and there were practically no visible 


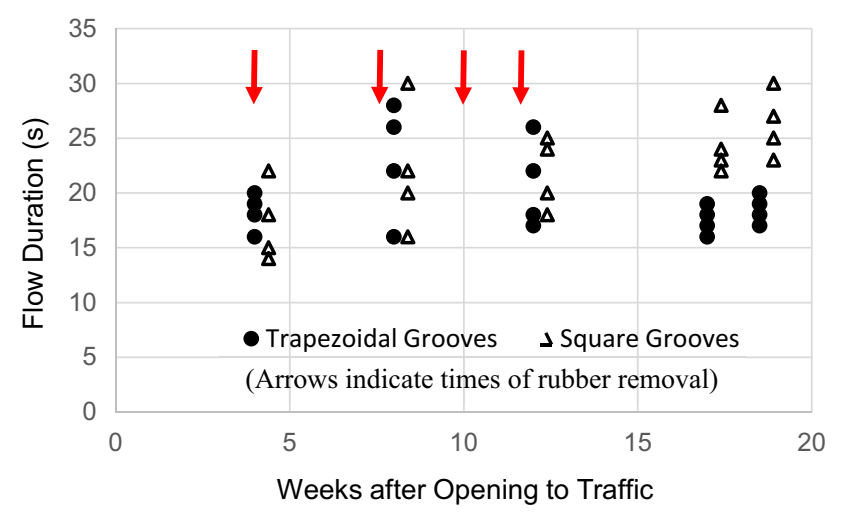

Fig. 6 Flow measurements on grooved pavements

deformation or distortion of the dimensions of the grooves under the actions of aircraft traffic and high pressure water-jet rubber removal operations. Changes in the dimensions of the flow channels of the grooves occurred due to the accumulation of rubber deposits, but the sizes of the channels were restored once the rubber deposits were removed.

4. Rubber deposit build-up-The effectiveness of pavement grooves are affected by accumulation of rubber deposits from aircraft tyres. The pattern of pavement grooving has an effect on the rate of rubber deposit build-up, which in turn affects the deterioration rate of skid resistance and the frequency of rubber removal operations. During the monitoring phase, attempts to measure the amount and thickness of rubber deposits were unsuccessful. This was because it was practically impossible to manually scrape the hardened rubber deposit from the pavement surface, or measure the thickness of the deposits. Hence, only skid resistance tests and visual inspections were made as indirect assessments of the degree of rubber deposit accumulation. The widths and depths of both the square and trapezoidal grooves were reduced due to the accumulation of rubber deposits. However, since the square grooves were narrower in their top width, some closing up of the square grooves occurred while none was observed on the trapezoidal grooves. This offers an explanation to the lower flow rates observed under the flow tests conducted as reported in point (2) above. On the ease of rubber removal, it was found that the shape of the trapezoidal grooves with their wider inlet openings led to a more thorough cleaning of the rubber deposit during rubber removal operations. In comparison, the narrower square grooves presented some difficulty for the rubber removal machine in cleaning and clearing the rubber deposits.

\section{Summary Remarks on Findings of Study}

The main aim of the analytical study and the field trial was to assess the operational safety performance and maintenance benefits of the square- and trapezoidal-grooved runway pavements. The findings from these studies are summarized below:

- The analytical evaluation of the hydraulic properties was performed based on the flow channel dimensions of the two groove designs. While the two designs have identical cross-sectional areas, the trapezoidal grooves were found to have slightly superior geometric properties by having $32.9 \%$ wider inlet opening, and $28.0 \%$ less wetted perimeter.

- A finite element simulation model of outflow meter revealed that the trapezoidal grooves have about $4.5 \%$ higher flow capacity than the square grooves for the range of inlet water pressures from 800 to $1600 \mathrm{kPa}$. This finding is consistent with the preceding finding concerning the differences in flow channel properties of the two groove designs.

- Skid resistance analysis was performed using a finite element skid resistance simulation model for runway pavements with surface water depths of 5 and $10 \mathrm{~mm}$ respectively. The analysis shows that the squaregrooved pavement has marginally higher skid resistance when the aircraft speed is lower than approximately $100 \mathrm{~km} / \mathrm{h}$, but the trapezoidal-grooved pavement produced higher skid resistance at speeds higher than $100 \mathrm{~km} / \mathrm{h}$. Since normal aircraft landing speeds are higher than $100 \mathrm{~km} / \mathrm{h}$, the trapezoidal grooves offer a slight advantage over the square grooves in terms of wet-weather runway operational safety.

- Using the same finite element skid resistance simulation model, the hydroplaning speeds on the two grooved surfaces were estimated. It was found that the trapezoidal-grooved surface provided about $3 \%$ higher hydroplaning speed than the square-grooved surface. Both grooved surfaces produced significantly higher hydroplaning speeds than an ungrooved surface.

- The field trial confirmed the significantly improved skid resistance performance of the two grooved surfaces over an ungrooved surface. Grooving of the test pavement sections improved the skid resistance of the original ungrooved from a Skid Number of $\mathrm{SN}=62$ to an $\mathrm{SN}$ value of about 70 .

- Field measurements of flow capacities of the two grooved surfaces were made in terms of the flow times between two pre-specified levels of an outflow meter. The results clearly showed that the trapezoidal-grooved 
pavement had a shorter flow time, and hence a higher flow capacity, than the square-grooved pavement when both types of grooved pavement were effected by accumulation of rubber deposits.

- Dimensional checks of the grooves showed that the asphalt mixtures in the two types of grooved were able to hold well under the actions of aircraft traffic loading and rubber removal operations. There were no visible signs of surface deformations or distortions of the grooved pavements.

- Physical manual measurements of rubber deposit buildup were not possible on the grooved pavements, and only indirect assessment based on visual inspections could be made. The sizes of flow channels of the square-grooved pavement was more adversely affected than those of the trapezoidal-grooved pavement. Some closures of the square grooves by rubber deposits were observed, while such groove closure was not found in the trapezoidal-grooved pavement. It was also found that the trapezoidal grooves permitted easier cleaning and clearing of rubber deposits. These observations suggest that maintenance efforts in terms of frequency of rubber removal and ease of rubber removal are favorable for the case of trapezoidal-grooved pavement.

\section{Conclusion}

This paper has presented the findings of an analytical study and a field trial conducted to evaluate the operational safety performance and maintenance benefits of a trapezoidal runway groove design against the commonly adopted square groove design. Making use of finite element simulation models, the analytical study concluded that the trapezoidal groove design is superior to the square groove design in terms of wet-weather runway operation safety. The former has higher flow capacity, higher hydroplaning speed, and higher skid resistance at normal landing aircraft speeds of more than $100 \mathrm{~km} / \mathrm{h}$, although the differences in all three aspects are only of the order of about 3-5\%. The field trial conducted at Singapore Changi Airport provided valuable assessments of the field performance and maintainability of the two types of grooved pavements. Both types of grooved surface were able to hold well against the actions of aircraft traffic loading and rubber removal operations. However, compared with the square grooves, the trapezoidal grooves were less affected by accumulation of rubber deposits, provided higher flow capacity, and required lower frequency of rubber removal operations. In summary, the analytical study and field trial showed that the trapezoidal grooves produced improved performance for wet-weather runway operations, were less affected by rubber deposits, and required less maintenance efforts. Since both the square and trapezoidal grooves can be cut using the same machine with the same resources and construction time, it is recommended that trapezoidal grooves be adopted for new and rehabilitated runways in developed as well as developing countries to achieve better runway performance with reduced maintenance efforts.

\section{References}

1. Van Es GWH, Roelen ALC, Kruijsen EAC, Giesberts MKH (2001) Safety aspects of aircraft performance on wet and contaminated runways. Publication NLRTP-2001-216 Netherlands National Research Laboratories

2. Horne WB, Whitehurst EA (1969) Highway and runway traction studies: the problem, history and NASA Program. Pavement Grooving and Traction Studies, NASA SP-5073, National Aeronautic and Space Administration, Washington, D.C., pp 3-19

3. Agrawal SK (1986) Braking performance of aircraft tires. Progr Aerosp Sci 23:105-150

4. International Civil Aviation Organization (2013) Aerodrome design and operations. Aerodromes, Vol. 1, Annex 14 to the Convention of International Civil Aviation, vol 6. ICAO, Montreal

5. Federal Aviation Administration (1997) Measurement, construction and maintenance of skid-resistant airport pavement surfaces. FAA Advisory Circular 150/5320-12C, Washington D.C

6. Horne WB, Brooks GW (1967) Runway grooving for increasing tire traction-the current program and an assessment of available results. NASA Langley Research Center, Virginia

7. Agrawal SK, Daiutolo H (1981) Effects of groove spacing on braking performance of an aircraft tire. Transp Res Rec 836:55-60

8. Agrawal SK (1981) The Braking performance of an aircraft tire on grooved portland cement concrete surfaces. FAA-RD-80-78, Federal Aviation Administration, Washington, D.C

9. Allen CR, Quillen JW (1969) Problem areas associated with the construction and operation of the landing Research runway at NASA Wallops Station. Pavement Grooving and Traction Studies, NASA SP-5073, Paper No. 8

10. FAA (1969) Environmental Effects on Airport Pavement Groove Patterns. Engineering Center. Report-Federal Aviation Administration, Report No. FAA-RD-69-37

11. Melone R (1979) Surveys of grooves in 19 bituminous runways. final report, Naval Air Engineering Center. Report-Federal Aviation Administration, Systems Research and Development Service, FAA-RD-79-28

12. Emery SJ (2005) Asphalt on Australian Airports. Australia asphalt paving association pavement industry conference, Surfers Paradise, Queensland

13. Patterson JW (2012) Evaluation of trapezoidal runway grooving. FAA-TC-TN12/7, Federal Aviation Administration, Washington, D.C

14. Pasindu HR, Fwa TF, Ong GP (2012) Analytical evaluation of beneficial effects of runway pavement grooving on aircraft braking Distance. In: Transportation Research Board 91st Annual Meeting Compendium of Papers. Washington, DC: Transportation Research Board

15. Horne WB, Yager TY, Taylor GR (1968) Review of causes and alleviation of low tire traction on wet runways. NASA Technical 
Note NASA TN D-4406. National Aeronautic and Space Administration, Washington, D.C

16. Ong GP, Fwa TF (2007) Wet-pavement hydroplaning risk and skid resistance: modeling. J Transp Eng 133(10):590-598

17. Fwa TF, Ong GP (2008) Wet-pavement hydroplaning risk and skid resistance: analysis. J Transp Eng 134(5):184-190

18. Pasindu HR, Fwa TF, Ong GP (2011) Computation of aircraft braking distance. Transp Res Rec 2214:126-135

19. ANSYS Inc. (2009) ANASYS CFX solver theory guide. ANSYS CFX Release 12.1. ANSYS Inc, Canonsburg

20. Pinkus O, Sterlicht B (1961) Theory of hydrodynamic lubrication. McGraw-Hill, New York
21. Launder BE, Spalding DB (1974) The numerical computation of turbulent flows. Comput Methods Appl Mech Eng 3:269-289

22. ADINA R\&D Inc. (2009) ADINA theory and modeling guide volume I: ADINA solids and structures. ADINA R\&D Inc., Watertown

23. Fwa TF, Low C, Yeung C, Choong CY (2015) Grooving of airfield pavement at Changi Airport. Paper accepted for presentation at 9th international conference on road and airfield pavement technology, Dalian, China, 9-12 Aug 2015 